\title{
Development of an Integrated Framework to Investigate Enterprise Information Systems Adoption: Managers' Insights
}

\author{
Salam Abdallah \\ College of Business Administration, Abu Dhabi University \\ Al Ain, United Arab Emirates \\ Email: salam.abdallah@adu.ac.ae \\ Bushra Jaleel \\ College of Business Administration, Abu Dhabi University \\ Al Ain, United Arab Emirates
}

\begin{abstract}
This study attempts to isolate the factors contributing to successful adoption of EIS by gathering the perspectives of senior professionals working with such systems. This paper uniquely uses dimensional analysis to find that organizations require correctly and completely implemented systems that are widely accepted by the end users and result in significant process improvements. These process improvements are likely to be controlled by various organizational factors and should be regularly assessed in terms of performance indicators for growing or changing needs of the organization.
\end{abstract}

Keywords: Critical success factors, Enterprise Information Systems, Information Systems Adoption, Dimensional Analysis, UAE, Qualitative Research

\section{Introduction}

Enterprise Information Systems (EIS) in their different forms, such as: enterprise resource planning (ERP), customer relationship management (CRM) and supply chain management (SCM), are highly integrated complex systems and have become essential for successful business operations. The benefits of an EIS project are enormous; having both tangible and intangible values. ${ }^{1}$ EIS have the ability to drive efficient and effective daily business operations. These systems are used to streamline internal and external business operations and help achieve competitive advantage by deriving the business strategies and initiatives. They also provide visibility and flexibility. ${ }^{2}$

These benefits can only be reaped if companies survive the implementation hurdles of such complex systems. The downside of such systems is the high rate of failure leading to either financial damage or disruption to the business operations. The success rate of ERP implementations does not normally exceed fifty percent. $^{3}$ Those projects that succeeded have reasons attributed to a multitude of factors that are interrelated involving both technological and human factors.

There is a growing body of knowledge on EIS implementations and successful factors from a western context, but very little on the experiences of organizations captured from organizations in the United Arab Emirates (UAE). According to IDC $^{4}$, a research firm, the UAE IT services market is expected to expand at an average annual growth rate of 11.4 per cent to exceed $\$ 2$ billion in 2015. IT spending reached $\$ 7.3$ billion in 2013 compared to $\$ 6.5$ billion last year. With such large investment, studies that provide insights on EIS implementations should be useful to managers to assist them in maximizing the return on investment. The 
success of EIS projects is of great relevance in IS research and practice. Therefore, this study aims at gaining insights into practitioners' experience what constitutes as the critical success factors of EIS adoptions, and if these factors tend to be interrelated.

\subsection{Significance and Purpose of the Study}

The purpose of this study is to determine what is involved in the successful adoption of enterprise information systems. The results of this study would be of interest to both practitioners and academics who are involved in designing, implementing, or using such systems. Although many studies have previously attempted to identify critical success factors of EIS adoption, this study is unique in that it aims to present an integrated view of factors and activities that are required for successful adoption. This will be achieved using a qualitative research design and application of dimensional analysis, a theory building technique pioneered by Schzatman. ${ }^{5}$ This study also aims to add to this body of work by by tapping into the insights of EIS practitioners in the UAE, a demographic that is rarely studied in the literature.

This study acknowledges that there is no universal theory for successful EIS adoption that can be applied to all organizations; however, the findings of this study bring in a new perspective to view successful EIS implementation from different areas. This study is probably the first of its nature in terms of its context and the methodological research approach. This research provides managers with an integrated framework to view the entire EIS implementation that may lead to successful adoption. Hence, it is hoped that managers and researchers will use this framework to guide implementations or to be used as a research lens for further research and development.

The remainder of the paper is organized as follows; first the paper reviews existing literature on common success factors that facilitate EIS adoption, followed by explanation of the research method used, with special emphasis on using dimensional analysis for qualitative data analysis. The results and the derived explanatory matrix are discussed next, and the findings of the current study are assessed in light of existing literature. Finally, the research limitations and areas for future research are identified.

\section{Background}

There are many reasons why organizations need to implement EIS. Such reasons include data centralization, business integration (internal and external), cost reduction, and the ability to respond to customers' requests. ${ }^{6}$ EIS systems allow organizations to have a more efficient business process. When combined with other tools, it allows for better data analysis and improved access to information for real time decision-making, and efficient inventory through the supply chain. ${ }^{7,8,9}$ In general, EIS increase the overall efficiency and effectiveness of organizations ${ }^{10}$ and provides them with flexibility to react to changing business environment ${ }^{11}$ and deliver high quality products. It is also stated that EIS allows for continuous environmental scanning, vision formulation, enterprise communication, business process alignment, SWOT analysis, stakeholders' engagement, performance measurement and values assessment. $^{12}$

A critical success factor (CSF) is a factor or set of procedures which are required for successful project implementation. ${ }^{13}$ There is no general consensus on what critical success factors should be considered for EIS implementation. The extant literature has revealed various sets contributed from various studies. To get a glimpse of these factors, a few studies are listed below. Normally these studies reveal nine to sixteen factors ${ }^{14}$, and may be grouped into categories such as product, process and service. $^{15}$

In a study on 29 firms using SAP systems, it was noted that several success factors such as, project management approaches and appropriate culture and organizational readiness contribute to the success of SAP EIS implementations. ${ }^{1} \quad$ A study also identified eleven factors that are critical to ERP implementation success: ERP teamwork and composition; change management program and culture; top management support; business plan and vision; business process reengineering; customization; effective communication; project management; software development, testing, and troubleshooting; monitoring and evaluation of performance; project champion; and appropriate business and information technology legacy systems. ${ }^{16}$ Similarly, a study on manufacturing users of ERP systems identified eight constructs needed for successful EIS adoption (strategic information technology planning, executive commitment, project management, 
information technology skills, business process skills, ERP training, learning, and change readiness). ${ }^{17}$

Critical success factors were also identified in the context of system adoption. For instance, a study proposed fourteen success factors for successful adoption of information systems, namely; definition of business goals, establishment of an executive management planning committee, thinking of implementation as research and development, use of cross-functional teams, stocking implementation teams with the best and smartest workers, alignment of everyone's interest by giving mid-level management hands-on responsibility, constant communication with teams and end users, excellent project management, choice of partners, extensive education and training, management with data, measurement of the right things, establishment of aggressive achievable schedules, and no fear for change. The same study also identified nine failure factors to be avoided (top management failure, poor project management, lack of education and training, people not wanting the new system to succeed, unrealistic expectations about implementation, inaccurate data, attempts to automate existing redundant or non-value-added processes, mismatch between the business and ERP system selected, and technical difficulties) which acted as hurdles to IS adoption. ${ }^{18}$

EIS implementation are also affected by cultural factors as noted in a study where the author argued that critical success factors determined in a Chinese context are similar to their Western counterparts, but with elements of Chinese cultural characteristics. ${ }^{19}$ Other studies highlight specific aspects, such as an integrated, process-oriented approach to reduce resistance to ERP systems adoption ${ }^{20}$ or the need for integration with legacy systems. ${ }^{21}$

Although, the literature on EIS is considered mature ${ }^{22}$, researchers and practitioners will continue to seek ways to improve EIS implementations, to maximize values for all stakeholders. The above sampled factors are important to guide project managers; however, these were mostly captured from western perspectives and do not provide a more holistic view as presented in this study. Due to the limited coherence in results presented in published research, as well as the dearth of literature focusing on EIS adoption in the Arab World, this study aims to make use of dimensional analysis to study the concept of EIS adoption.
Dimensional analysis is a technique pioneered by Schatzman's ${ }^{5}$, which provides a very structured and organized perspective for theory building and helps to formulate models that can explain concepts in a particular context, in terms of underlying processes and consequences, and in light of certain conditions. The technique, also referred to as natural analysis, is normally used to explain social and behavioral phenomenon $^{23}$, and has been presented in the literature as an alternative to, the more widely used, grounded theory. ${ }^{24}$ The technique is one of the few approaches that can systematically transform empirical data into abstract concepts.

In comparison to grounded theory, dimensional analysis is considered a more practical approach to theory building, as it allows researchers to make use of existing theoretical assumptions while formulating new theories for understanding and explaining concepts. ${ }^{25}$ Despite its structural and systematic foundation, and the clarity of its results, in comparison to other qualitative research techniques, dimensional analysis has not been very widely used. This lack of use is believed to be due to the limited documented sources that provide details on how the technique should be applied. ${ }^{25}$

Perhaps the most comprehensive outline of using dimensional analysis for qualitative analysis is provided in an article ${ }^{25}$ by students of Schatzman. They explain that that, essentially, when studying a phenomenon, dimensional analysis systematically transforms observed events or data related to the phenomenon from its descriptive state to an explanatory form. First the data is reviewed to assign open codes to all relevant events or observations that resulted from data collection. These codes are organized into axial codes in terms of the main attributes and properties they share and act. These codes act as preliminary dimensions or components of the underlying phenomena. Next, axial codes which appear to be theoretically or logically related are merged together and assigned theoretical codes. The analysis is repeated till interrelationships between the dimensions become apparent and depict explanatory power. These theoretical codes can then be organized into four conceptual components; context, conditions, processes, and consequences, which are illustrated using a matrix. 


\section{Method}

Since the main objective of this study is to determine factors that may contribute to the successful implementation and adoption of enterprises systems, a qualitative approach with multiple case studies was adopted. As is commonly known, case studies are suitable for exploring new phenomen ${ }^{26}$ and where theory is not available or under development. ${ }^{27}$

Three large organizations were selected from Abu Dhabi province in the United Arab Emirates. Twenty eight participants were interviewed using a semistructured format composed of open-ended questions. The demographic information of the participants is summarized in Table 1.

Table 1. Demographic Information

\begin{tabular}{|c|c|}
\hline Sample Size & 28 \\
\hline Male & $21(75 \%)$ \\
\hline Female & $7(25 \%)$ \\
\hline \multicolumn{2}{|l|}{ Designation } \\
\hline Senior IS Specialist & $11(39.29 \%)$ \\
\hline Mid-Level Manager & $8(28.57 \%)$ \\
\hline Upper-Level Manager & $9(32.14 \%)$ \\
\hline Average Experience with EIS & 9.04 years \\
\hline $1-5$ years & $32 \%$ \\
\hline $5-10$ years & $43 \%$ \\
\hline $10+$ years & $25 \%$ \\
\hline \multicolumn{2}{|l|}{ Information System } \\
\hline Oracle & $52.38 \%$ \\
\hline HRIS & $19.05 \%$ \\
\hline MedNext & $9.52 \%$ \\
\hline Maximo & $4.76 \%$ \\
\hline Documentum & $7.14 \%$ \\
\hline Others & $7.14 \%$ \\
\hline
\end{tabular}

The participants were mostly male and held either senior or high level management positions at large sized organizations in the UAE. The participants were engaged with a variety of enterprise systems either from technical, user or managerial perspectives. All those interviewed were in a position to discuss some aspects on their EIS experience. Most of the participants (43\%) had six to ten years of experience with EIS, 32\% had one to five years of experience, and 25 had more than ten years.
The participants were asked to express and reflect on issues related to successful implementation and adoption of EIS at their organizations. The next section documents and structures the responses of participants from the interview in order to aid further analysis. Wherever used, verbatim participant responses are italicized in inverted commas.

\section{Results}

Based on the objectives of the study, the interview revolved around factors that could lead to successful implementation and adoption of EIS. Participants also discussed common measures of measuring this success in their organizations, and although these responses varied based on the participants' individual experiences with the systems employed at their respective organizations, some common themes emerged which are discussed below.

Successful implementation of the system emerged as the first factor contributing to successful adoption of an EIS. Participants in this study insisted that EIS adoption relies heavily on its successful implementation in the organization, noting that while the organization is expected to conform to using the IS and commit to the change, successful implementation of EIS requires significant support from the EIS service provider; "support from IT (department/vendor) plays a big role in helping the users in their issues and fulfilling their needs and requirements".

At the same time, the respondents clarified that implementation of an IS is not the sole responsibility of the EIS service provider or system technicians. Going beyond the technical factors in EIS implementation, a clear requirement analysis and involvement of end users in designing the system were also identified as essential contributors to successful implementation of an EIS. As a respondent notes; "Involve the end users with the implementation stages starting from the functional specifications until the IS selection process".

Clearly, a successfully implemented system will add little to work processes if the users are unwilling to adapt to the change. Thus, a second factor identified by this study for successful adoption of EIS is user acceptance of change. Participants noted that willingness to accept and use the system will be enhanced when the EIS is known to support workflow processes and is perceived as useful. EIS have great potential to contribute to human resource development 
and it is asserted that management should provide "training, education, and updated information" to its end users in order to clearly explain how newer technology can be beneficial for them. However, the respondents have expressed varied opinions regarding the best means to induce change acceptance, ranging from continuous management support to mandatory use of the system, as a respondent notes that successful adoption of information systems requires that it is the "only available tool to carry out the daily work".

Another factor contributing to successful adoption of EIS is process improvements that result from the system. Since process improvement is often one of the prime objectives of installing an EIS, systems that do not enhance the workflow processes and are not upgraded to encompass organizational requirements are of little use to the organization. Participants asserted that use of information systems is expected to result in "efficiency in the speed of transactions", in addition to "integration between different business functions and processes". Thus, the system's adoption also depends on a periodic assessment of how well the system improves existing processes.

Lastly, respondents noted the role of system's performance as a factor influencing EIS adoption, specifying that successful adoption of an EIS requires that the system is consistently evaluated and improved to cater to the organization's needs. Several indicators have been suggested that quantify a system's performance, including "turnaround time, number of complaints, employee satisfaction, and downtime data lost". The respondents insisted that all IS must be "professionally managed" to entail any form of benefit. It is also suggested that employees should be "encouraged to propose solutions to improve the IS". It is believed that involving employees' input in making changes to EIS facilities acceptance of change, also encouraging information system adoption.

All in all, a review of these responses suggests that successful adoption of information systems is largely associated with four key factors, namely; successful implementation of the system, end-user acceptance, regular evaluation of the system, and process improvements resulting from the system. The participants identified that successful implementation of an EIS is vital to its effective use in the future. They also noted that acceptance of change dictates the attitude of end users towards updated technology and directly relates to its usage rate. Process improvement was identified as one of the prime motives behind installation of an EIS and regular evaluation of the system's performance is considered crucial to assess the accuracy and reliability of the system, as well as its capability to fill in preexisting gaps.

These factors also emerged as largely interdependent. For instance, management perceptions in this study clearly highlight that a system would need to be correctly implemented in order to be readily adopted by the users and bring about significant process improvements, while without significant process improvements, it would be hard to judge the effectiveness of the implemented system. Similarly, regular evaluations of the system's performance are expected to improve its correct implementation. Therefore, as opposed to isolated factors determining EIS adoption, it appears that these four factors exist as a series of streamlined activities which govern successful IS adoption. Evidently, the process of successful implementation, followed by change acceptance, can be expected to bring about process improvements, which need to be continuously evaluated for possible optimization or upgrading of the system. This is illustrated in Figure 1.

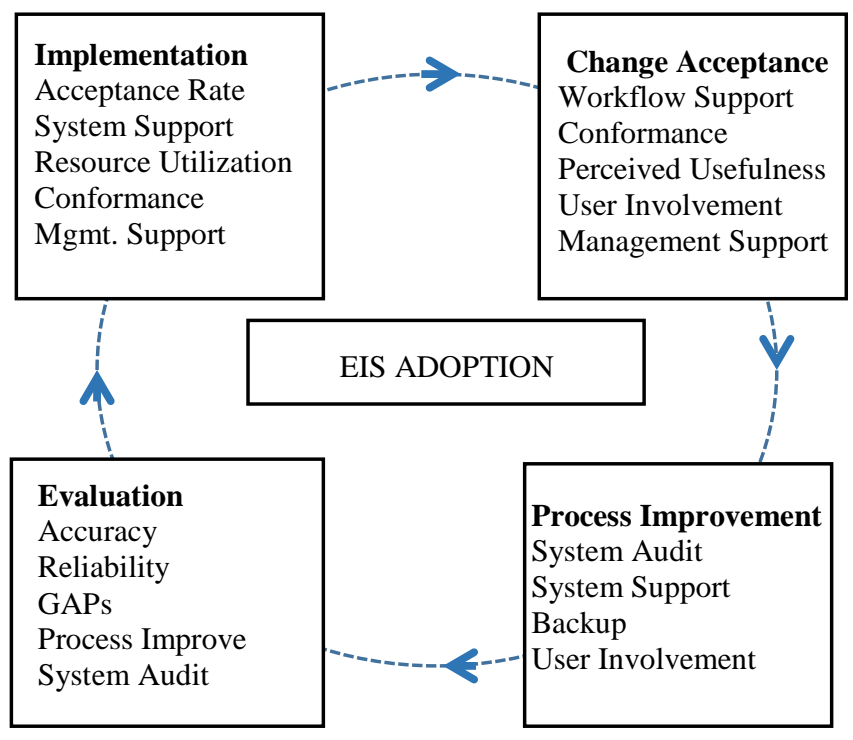

Fig.1. EIS Adoption - A Continuous Process 
Thus, successful implementation of the system and wide acceptance of change by the organization are decisive for EIS adoption. Additionally, these factors, coupled with resulting work improvements and periodic evaluation of the system set the theoretical boundaries to weigh the success of EIS adoption in an organization, and facilitate the explanatory power of the dimensional analysis performed in the next section.

\section{Dimensional Analysis}

To perform dimensional analysis, all participants' responses were entered in a word processing software and scrutinized to apply open codes to all relevant words and phrases. Essentially, the first statement was read and the major theme present in that statement was assigned a code. The next statement was then reviewed in a similar manner to decide if it matches the description of the previous code or if it should be assigned a new code. In this way, a total of 253 open codes were manually assigned to the data set by carefully reading the responses from the sampled organizations. Next, by means of constant comparison, axial coding was performed, whereby open codes that were reasonably similar in theme and function were rearranged, merged and linked. This process resulted in a comprehensive list of 72 axial codes.

The next step required creation of theoretical codes, which could be assigned to represent theoretically and logically related axial codes. For this purpose, each axial code was reviewed in terms of the role it plays in the successful adoption of an EIS. Theoretical coding resulted in 15 groups of codes that were aptly labeled to define their content. Finally, as is required for dimensional analysis, these theoretical codes were classified into four main conceptual components; context, conditions, processes, and consequences. This categorization of data into relevant coding schemes is presented in Table 2.

To further structure the analysis, Schatzman (1991) encourages the use of an explanatory matrix, a graphic representation of the four conceptual components (context, conditions, processes, and consequences) under a unifying theme called the Perspective. As stated earlier, perspective in dimension analysis acts as the vantage point for studying a concept, and is normally stated on the top of the matrix. Trotta (2007) notes that for identifying the perspective, all dimensions should be given theoretical consideration, however, it is important that the perspective meets the necessary criteria of being open, inclusive, and present in all other dimensions.

This study's explanatory matrix, as illustrated in Figure 2, is set under the perspective of 'EIS Adoption Success Factors' mainly because it fits the purpose of the study well and remained the focal point of discussion throughout the interviews.

After defining the perspective, the remaining matrix is used to illustrate the four conceptual components. Specifically, the matrix highlights the context of the current analysis, and specifies the underlying processes and subsequent outcomes of successful adoption of an information system, in addition to the conditions that may restrict system adoption. These are discussed below:

Conditions: the study has identified three main conditions which appear to influence the processes leading to EIS Adoption, namely, system characteristics, user involvement, and system usability. System characteristics refer to the technical aspects of the EIS which define its adaptability and performance. The respondents insisted that "customization" and "updatability" are key characteristics required in a good EIS. The condition of user involvement notes the contribution of end users in creating and developing the system and defining its requirements. The study suggests that involving users in important areas tends to positively influence their commitment to and attitude towards using the EIS. Lastly, system usability as a condition is governed by the system's quality, available technical support, and the ease of use of the system. By and large, respondents favored having EIS with familiar interface designs, clear functions, and timely support.

Processes: Need assessment, system deployment, training, updates, and post implementation management are the five processes identified in this study. Need assessment is the process of requirement analysis whereby the goals and functions of the system are clearly defined and assessed in terms of significance. This process requires clear and accurate definition of needs and accompanies plans to fill existing gaps in performance. System deployment is the process of formally implementing the system and tends to automate the major business functions in an organization. Respondents note that this process needs to be "professionally monitored" and must ensure "proper integration” with existing systems. 
Table 2: Components of the Explanatory Matrix in Dimensional Analysis

\begin{tabular}{|c|c|c|}
\hline \multirow{2}{*}{$\begin{array}{c}\text { Matrix } \\
\text { Component } \\
\end{array}$} & \multicolumn{2}{|r|}{ Coding Levels } \\
\hline & Theoretical Codes & Axial Codes \\
\hline \multirow[t]{8}{*}{ Context } & & System Acceptance Rate, System Support \\
\hline & Implementation & Resource Utilization, Management Support \\
\hline & & Conformance \\
\hline & & Workflow Support, Conformance, Perceived Usefulness, User \\
\hline & Acceptance & Involvement, Management Support, Human Resource Development \\
\hline & Improvement & System Audit, System Support, User Involvement \\
\hline & & Accuracy, Reliability, GAPs, Process Improvement, System Auditing \\
\hline & Evaluation & \\
\hline \multirow[t]{3}{*}{ Conditions } & System Characteristics & $\begin{array}{l}\text { Adaptable, Updatable, Performance, } \\
\text { Customization, Interface with ERP }\end{array}$ \\
\hline & User Involvement & $\begin{array}{l}\text { System Development, Propose Solutions } \\
\text { Appreciation, Commitment }\end{array}$ \\
\hline & System Usability & Language, System Support, User Interface \\
\hline \multirow[t]{5}{*}{ Processes } & Need Assessment & Clear, Accurate, Timely, GAPs \\
\hline & System Deployment & $\begin{array}{l}\text { Automate, Backup, Integrate, Doc Management } \\
\text { Short Iterative Evolution, Best Practices }\end{array}$ \\
\hline & End User Training & Processes, Benefits, Shortcuts \\
\hline & System Updates & $\begin{array}{l}\text { Notification, Regular, Training, Useful } \\
\text { Database Tuning }\end{array}$ \\
\hline & $\begin{array}{l}\text { Post Implementation } \\
\text { Management }\end{array}$ & $\begin{array}{l}\text { Planning, Compliance, Quality Control } \\
\text { Motivation, Continuous Evaluation, } \\
\text { System Health, Optimization }\end{array}$ \\
\hline \multirow[t]{4}{*}{ Consequences } & & Process Improvement, Conformance \\
\hline & Key Performance & Transparency, User Satisfaction, \\
\hline & Indicators (KPIs) & Users Development, ROI, Value Added \\
\hline & System Output & $\begin{array}{l}\text { Reporting Tools, Historical Database } \\
\text { Graphics, Business Intelligence, Data Quality }\end{array}$ \\
\hline
\end{tabular}

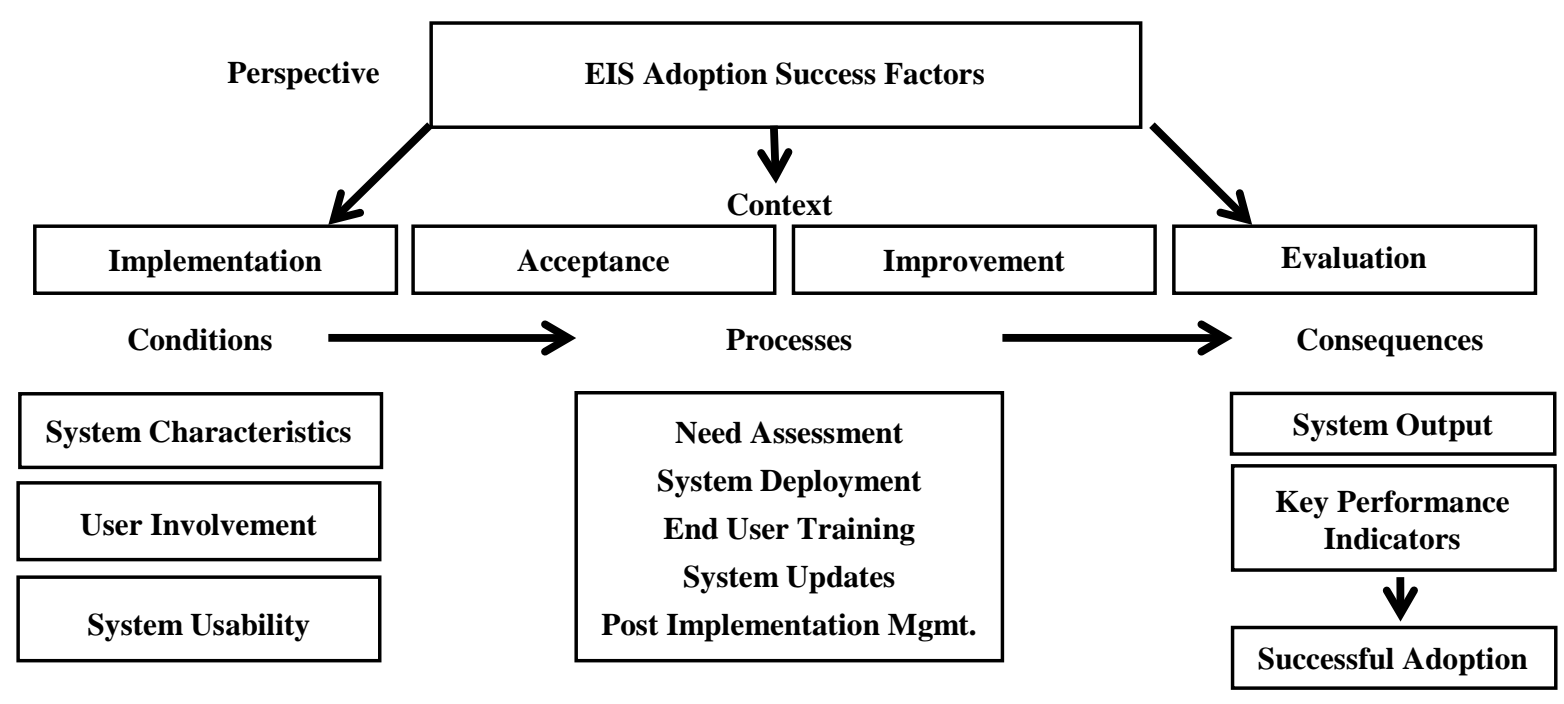

Fig.2. Explanatory Matrix 
Subsequently, users need to be adequately trained in using the EIS, which is the third important process identified in this study. Training should not only highlight how the system should function, but should also bring forward the main benefits for the employees of using the system. Next is the process of system updates, which ensures that the organization's EIS is adept in making use of the current technology and administers the use of all required business functions. Respondents assert that any system updates must be followed by appropriate training programs for the users. Lastly, the process of post implementation management governs the system's health, and involves continuous evaluation of the system for its current usage, as well as its planned use in the future.

Consequences: Successful adoption of EIS implies that the system's output should positively contribute to key performance indicators. A firm's performance indicators are uniquely defined based on their operational and strategic objectives. Common indicators highlighted by the respondents include human resource development (HRD), return on investment (ROI), transparency, and process improvement. These indicators can always be compared with industry benchmarks for an overall assessment of successful IS adoption, as a respondent notes; "in comparison to the exiting companies in the market, either local or international, our systems should be considered as the best”.

Based on the results of this study and the dimensional analysis, it is apparent that successful EIS adoption relies on its successful implementation, and is often judged by its subsequent use to carry out every day operations. This research outlines two fundamental notions that become part of this study's contributions and can serve as theoretical bases for future research work in this area. The first is the understanding that EIS adoption is a continuous process, based on a set of interrelated components and requires user involvement and regular assessments. The second is the role of organizational factors and key performance indicators in influencing the successful adoption of EIS in an organization. The following section elaborates on these as well as other important findings of this study in light of existing literature.

\section{Discussion}

\subsection{EIS Adoption - A Continuous Process}

In a study ${ }^{28}$ to investigate ERP adoption in Vietnamese firms, researchers defined EIS adoption as an innovation process, however, did not classify it as a continuous one. A continuous process involves a series of ongoing activities that progress in a definite order and repeated to provide the desired results as the process flows. As identified in this study, several authors have adopted a similar life cycle approach in ERP research, hinting the existence of a series of phases or evolutionary stages ${ }^{29}$ which can be considered as components of a continuous process. Typical phases are planning, implementation, stabilization, and enhancement ${ }^{30}$, all of which reinforce the main dimensions identified in the current study.

This study also links EIS implementation with change acceptance, and it can be argued that successfully implemented systems would present changes that are more readily acceptable by the organization. To boost change acceptance, the literature heavily advocates the role of senior management ${ }^{16,31,32}$, evidence of which is also presented in the current research. Studies focusing on critical success factors of IS implementation have also highlighted various other factors that define the success of an EIS $^{33}$, however, it is noted that firms usually invest in installing sophisticated systems, but do little to emplace a proper organizational change program. ${ }^{34}$ An organization that implements innovation and technology in its system cannot acquire a competitive edge unless it develops its human resource. $^{35,36,37}$ Here in lies the importance of training the end users and ensuring that the change is, in fact, accepted by the organization.

Once change in the organization is formally accepted, it is expected to result in improved work processes. A study also notes that the positive impact of EIS in an organization is one of the five key factors that determine the success of an EIS. ${ }^{38}$ Other factors highlighted in this study are availability of the system, system usage, user satisfaction, and diffusion of the system in the organization; all of which signify the importance of user involvement in defining the success of the system. Generally, benefits, barriers and risks all have important effects on user satisfaction. ${ }^{39}$

The last dimension identified in this study accounts for regular evaluation of the system. There is always a need for flexibility in the enterprise system, to allow for 
adapting and enhancing an IS after its implementation to meet user's requirements or functional discrepancies. ${ }^{40}$, 41, 42 EIS adoption has also been strongly linked with its perceived benefits in a study, where the authors note that these benefits must be taken into account when assessing the impact of an EIS. ${ }^{43}$ Any significant issues that come forward during this evaluation need to become part of system updates to be implemented in the future, thereby completing the EIS adoption process.

\subsection{KPIs and Organizational Factors}

As indicated earlier in the exploratory matrix (Figure 2), the study identifies five major processes in EIS adoption, namely; need assessment, system deployment, end user training, system updates, and post implementation management. Existing literature supports that these processes, as shown in Figure 3, jointly contribute to the achievement of key performance measures. While the process of need assessment establishes the requirements of the organization, effective system deployment is essential to prevent any technical failures. Training ensures users are competent enough to make use of the system, and the process of system updates and post implementation management ensures that the system remains effective in the long run.

It has been argued that the users should carry the responsibility of realizing the benefits from EIS implementations. ${ }^{44}$ To justify investments in EIS and to enhance its use, there is a need to conduct ex-post evaluation by identifying key performance indicators. ${ }^{45}$ The success of EIS implementation can be perceived in different ways ${ }^{15}$, but every organization that chooses to invest in any innovative technology does so to achieve certain objectives.

While previously some authors have defined EIS adoption only as the decision to adopt technological innovation $^{46}$, others have affirmed the cumbersome nature of the concept ${ }^{37}$, and it is believed that the quality of the system and its output cannot be ignored. ${ }^{47}$ The present study indicates that firms can have a variety of performance indicators, ranging from increased user satisfaction to higher return on investment, but formal definition of these goals is essential to contribute to the success of the system. ${ }^{48}$

The study has also identified some organizational factors (such as leadership style, employee capabilities, company resources, etc.) that can have a significant impact on IS adoption. These are indicated outside the dotted lines in Figure 3.

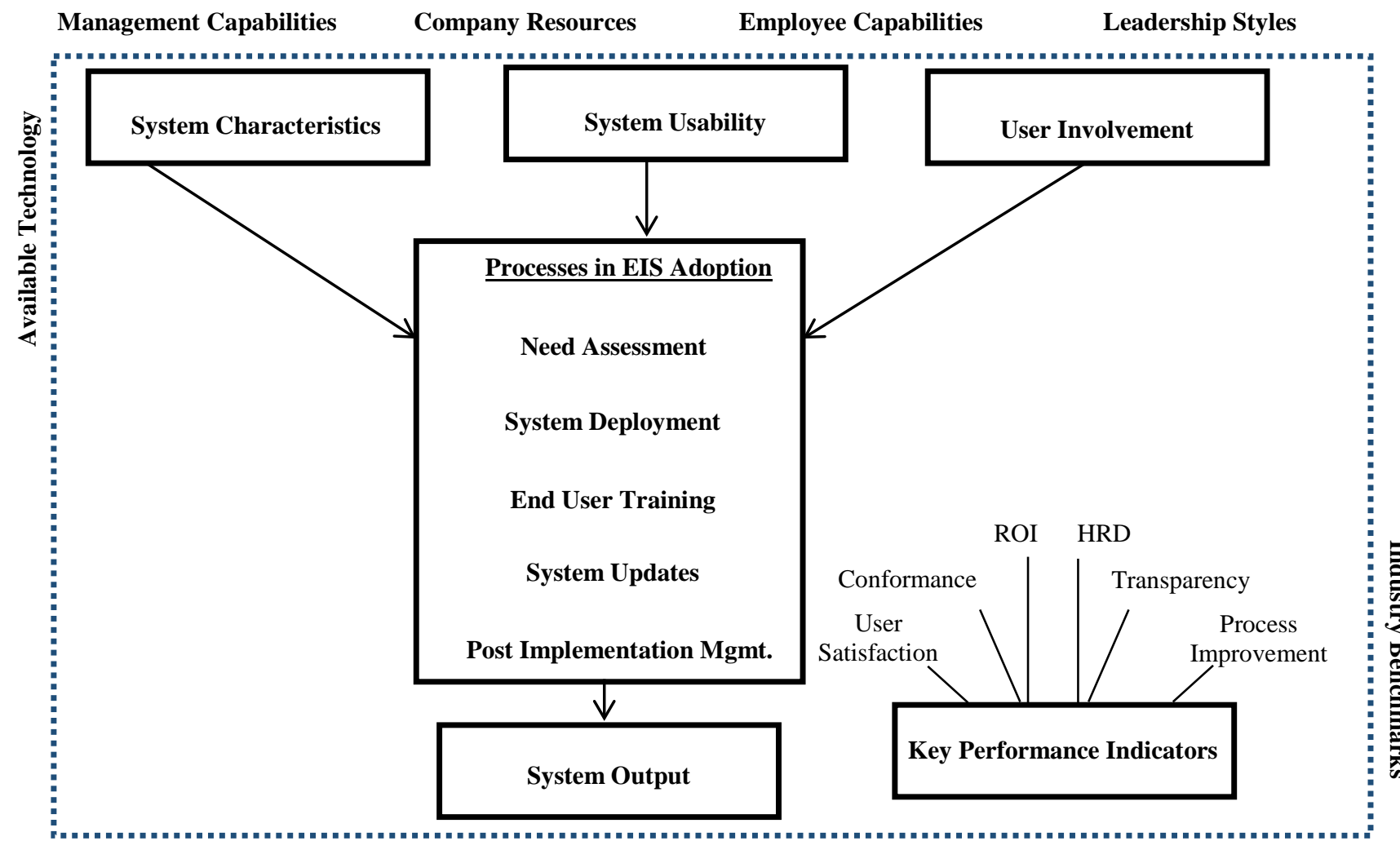

Fig.3. Key Performance Indicators and Organizational Factors 
It is believed that these organizational issues are more important than technical ones for successful adoption of an $\mathrm{IS}^{49}$, and has also been empirically supported by finding that bureaucratic leadership and procedural rigidity in organizations often leads to the failure of successfully implemented systems. ${ }^{6}$ It implies that to rectify such issues and yield benefits from these systems, organizational factors must always be taken into consideration. ${ }^{50,51}$

\section{Limitations and Areas for Future Research}

The interpretations of this study are subject to certain limitations. Firstly, only three organizations were invited for this study. Although a good representative sample of twenty-eight mangers was interviewed, the generalizability of this study remains restricted. However, since the goal of qualitative research is normally not generalization of the findings, but to provide rich descriptions of phenomenon by various participants who had experienced the phenomenon, the paper makes a valuable contribution by making a comprehensive assessment of the factors involved in successful EIS adoption.

Secondly, since this work is based on theoretical analysis, interpretations are subjective on the part of the researcher. Although care was taken to limit the subjectivity by involving multiple assessors in the coding phases, it is possible that similar work performed by others may yield different results. Lastly, as is the case in most empirical investigations, a causal relationship is very difficult to ascertain. Future research is recommended to empirically test the model presented in this study to establish its reliability and validity and to examine the relationship between the emerged categorized factors. The current findings can also be complemented by employing similar techniques to gather user or developer perspective to understand further the successful adoption of EIS.

\section{Conclusion}

This study has set out to develop an integrated framework to understand successful adoption of EIS projects. The framework emerged from qualitative analysis using rich data collected from twenty-eight practitioners. The results are uniquely presented in an integrated explanatory matrix that encompasses a large range number of critical success factors and were grouped into four conceptual components using dimensional analysis.

The study notes that successful EIS adoption in organizations requires correctly and completely implemented systems that are widely accepted by the end users and result in significant process improvements. These process improvements are likely to be controlled by various organizational factors and should be regularly assessed in terms of performance indicators for growing or changing needs of the organization. Key performance indicators must also be compared with industry benchmarks to ensure that performance standards are being maintained.

The findings of this study have significant implications for IS practitioners. EIS benefits can be achieved when the appropriate factors related to organizational conditions are considered to allow for successful process to take place. This research sheds light on various issues and offers an improved understanding of the condition, processes, and which should lead to positive consequences. Organizations that plan to implement EIS should ensure the organization environment conditions are appropriate for its implementation and check for their readiness. The results of this study may also help to predict or explain the relationship between the various, and somewhat comprehensive factors, involved in successful adoption of EIS.

Previous studies usually present CSF by using a fragmented approach rather than a holistic perspective as presented in this study. Practitioners could apply this study's framework to better understand the processes involved in EIS adoption. The academic community could also use the framework to investigate and understand issues influencing EIS project implementation and its outcome. 


\section{References}

1. V.B. Gargeya and C. Brady, Success and failure factors of adopting SAP in ERP system implementation, Business Process Management Journal, 11(5) (2005) 501-516.

2. K. Sandoe, G, Corbitt, and R. Boykin, Enterprise Integration (Wiley, New York NY, 2001).

3. V.M. Mabert, A. Soni, and M.A. Venkataramanan, Enterprise resource planning survey of us manufacturing firms, Production and Inventory Management Journal, 4(2) (2000) 52-88.

4. IDC, 'Worldwide Black Book'; (IDC: 2013)

5. L. Scahtzman, Dimensional Analysis: Notes on anAlternative Approach to the Grounded Theory in Qualitative Research, in Social Organization and Social Process. Essay in honor of Anselm Strauss,eds. D. Maines (New York, 1991).

6. T.H. Davenport, Putting the enterprise into the enterprise system, Harvard Business Review.16(4) (1998) 121-131.

7. T. Gattiker and D.Goodhue, What happens after ERP implementation: Understanding the impact of interdependence and differentiation on plant-level outcomes, MISQuarterly.29 (3) (2005), 559-585.

8. C.A. Lengnick-Hall, M.L. Lengnick-Hall, and S. Abdinnour-Helm, The role of social and intellectual capital in achieving competitive advantage through enterprise resource planning (ERP) systems,Journal of Engineering and Technology Management. 21 (4) (2004) 307-330.

9. A. Gupta, Enterprise resource planning: Rhe emerging organizational value systems. Industrial Management \&Data Systems. 100 (3) (2000) 114148.

10. K. Gourdin, Global logistics management: A competitive advantage for the new millennium (Blackwell, Oxford, 2000).

11. Z. Huang and P. Palvia, ERP implementation issues in advanced and developing countries, Business Process Management Journal.7(3) (2001) 276-284.

12. M. Fan, J. Stallaert, and A.B. Whinston, The adoption and design methodologies of componentbased enterprise systems, European Journal of Information Systems. 9 (2000) 25-35.

13. J.K. Pinto and D.P. Slevin, Critical factors in successful project implementation,IEEE Trans. Eng. Manage. 34 (1) (1987) 22-27.

14. C. Doom, K. Milis, S, Poelmans, and E.Bloemen, Critical success factors for ERP implementations in
Belgian SMEs, Journal of Enterprise Information

Management. 23 (3) (2010), 378 - 406.

15. W. Grafton and A. Bytheway, Factors affecting information systems' success,International Journal of Service Industry Management.7(1) (1996), 74 93.

16. F.F. Nah, J.L. Lau, and J. Kuang, Critical factors for successful implementation of enterprise systems,Business Process Management Journal.7 (3) (2001) 285-296.

17. J.K. Stratman and A.V. Roth, Enterprise resource planning (ERP) competence constructs: Two-stage multi-item scale development and validation, Decision Sciences, 33(4) (2002) 601-628.

18. E.J. Umble and M. Umble, Enterprise resource planning systems: A review of implementation issues and critical success factors, in Proceedings of the 32nd Annual Meeting of the Decision Sciences Institute (2001).

19. H.S. Woo, Critical success factors for implementing ERP: The case of a Chinese electronics manufacturer, Journal of Manufacturing Technology Management. 18 (4) (2007) 431-442.

20. A.M. Aladwani, Change management strategies for successful ERP implementation, Business Process Management Journal. 7(3) (2001) 266-275.

21. M. Themistocleous, Z. Irani, and R.M. O’Keefe, ERP and application integration, Business Process Management Journal. 7(3) (2001) 195-204.

22. B. Schlichter and P. Kraemmergaard, A comprehensive literature review of the ERP research field over a decade, Journal of Enterprise Information Management. 23(4) (2010) 486-520.

23. R.L. Trotta, Quality of death: A dimensional analysis of palliative care in the nursing home, Journal of Palliative Medicine. 10 (5) (2007) 11161127.

24. A. Shankar and C. Goulding, Interpretive consumer research: Two more contributions to theory and practice, Qualitative Market Research: An International Journal. 4(1) (2001) 7-16.

25. S. Kools, M. McCarthy, R. Durham, and L. Robrecht, Dimensional analysis: Broadening the conception of grounded theory, Qualitative Health Research.6(3) (1996) 312-330.

26. R.K. Yin, Case Study Research: Design and Methods (Sage, 1994)

27. I. Benbasat, D.K.Goldstein, and M.Mead, The case research strategy in studies of information systems, MIS Quarterly. 11(3) (1987) 369-386. 
28. T.S. Tran and C.T. Hoang, Information System Adoption within VietnameseSmall and Medium Enterprises(Lambert Academic Publishing, 2011)

29. F.D. Davis, R.P. Bagozzi, P.R. Warshaw, Development and test of a theory of technological learning and usage,Human Relations.45(7) (1994) 659-686.

30. L. Shaul and D. Tauber,Hierarchical examination of success factors across ERP life-cycle, in MCIS proceedings (2010).

31. R. Young and E.Jordan, Top management support: Mantra or necessity?, International Journal of Project Management.26 (7) (2008) 713-725.

32. E.S. Anderson, D. Birchall, S.A. Jessen, and A.H. Money, Exploring project success, Baltic Journal of Management.1(2) (2006) 127-147.

33. Esteves and J. Pastor, Organizational and technological critical success factors behavior along the ERP implementation phases, in Handbook of Enterprise Information Systems VI, eds. I. Seruca, J. Cordeiro, S. Hammoudi, and J. Felipe (Springer, Netherlands, 2006), p. 63.

34. S. Burgess, Managing information technology in small business: Challenges and solutions (Idea Group, Information Science, Hershey, 2002).

35. T.C. Powell and A. Dent-Micallef, Information technology as competitive advantage: the role of human, business and technology resources, Strategic Management Journal.18(5) (1997) 375-405.

36. R. Sharma, P. Yetton, The contingent effects of training, technical complexity, and task interdependence on successful information systems implementation, MIS Quarterly. 31(2) (2007) 219238.

37. S.A. Raza and C. Standing, Systematic problems in information technology adoption and use: a systems thinking perspective, in ECU Conference Proceedings (2008).

38. P. Poon and C. Wagner,Critical success factors revisited: success and failure cases of information system for senior executives, Decision Support System, 30 (4) (2001)393-418.

39. Ö. Y. Saatçığlu, What determines user satisfaction in ERP projects: Benefits, barriers or risks? Journal of Enterprise Information Management. 22 (6) (2009) 690-708.

40. M. Scherrer-Rathjeand A.B. Todd, An end-user taxonomy of enterprise systems flexibility: evidence from a leading European apparel manufacturer, Information Systems Management, 29(2) (2012) 8699.
41. J. Gebauerand F. Lee, Enterprise system flexibility and implementation strategies: Aligning theory with evidence from a case study, Information Systems Management. 25(1) (2008), 71-82.

42. L. Motiwalla and J. Thompson, Enterprise Systems Management: ERP Implementation in Organizations (Prentice Hall Publications, New York, 2009).

43. V. Kumar, B. Maheshwari, and U. Kumari, Enterprise resource planning systems adoption process: a survey of Canadian organizations, International Journal of Production Research. 40 (3) (2002) 509-523.

44. A. Ragowsky, P.S. Licker, and D. Gefen, Organizational IT maturity (OITM): A measure of organizational readiness and effectiveness to obtain value from its information technology, Information Systems Management. 29(2) (2012) 148-160.

45. S. Uwizeyemunguand L. Raymond, Linking the effects of ERP to organizational performance: Development and initial validation of an evaluation method, Information Systems Management. 27(1) (2010) 25-41.

46. J.L. Pierce and A.L. Delbecq, Organizational structure, individual attitudes and innovation, Academy of Management Review. 2(1) (1977) 2737.

47. W. H. DeLone and E.R. McLean, Information systems success: the quest for the dependent variable, Information Systems Research. 3(1) (1992) 60-95.

48. G. Thomas and W. Fernandez, Success in it projects: a matter of definition, International Journal of Project Management.26 (7) (2008) 733-742.

49. N. Doherty and M. King, An investigation of the factors affecting the successful treatment of organizational issues in systems development projects, European Journal of Information Systems.10 (3) (2001) 147-160.

50. A. Caruso and M.Marchiori, The adoption of information systems in SMEs: Organizational issues and success factors, in Proc 11th European Conference on Information System, (Naples, Italy, 2003).

51. H.J. Watson, R.K. Rainer, and G. Houdeshel, Executive Information Systems: Emergence, Development, Impact (Wiley, 1992). 